\title{
Determination of error level of ultrasonographic fetal weight estimation according to the seniority of residents in obstetrics and gynecology
}

\author{
Tayfur Çiftø, Muzaffer Temur®, Mehtap Yıldızbakan®, Ayşe Ülkü Türkerø, Sonay Öztaş®, Yeliz \\ Acarø, Sibel Üstünelø, Emin Üstünyurtø
}

Department of Obstetrics and Gynecology, University of Health Sciences, Bursa Yüksek İhtisas Training and Research Hospital, Bursa Turkey

\section{ABSTRACT}

Objectives: We consider the difference between estimated fetal weight and birth weight through the measurement according to the seniority of the residents in obstetrics and gynecology. In this study, we aimed to determine the fallibility of the residents according to their seniority years.

Methods: This research was planned as a prospective and approved by the Ethics Committee Ultrasonographic measurements were performed with ultrasound device and the estimated fetal weight was calculated with Hadlock 4 (BPD, HC, AC, FL) formula. Measurements were performed by the residents in the first, second, third and fourth year of training and repeated by the same specialist for each patient. Only those who gave birth within 48 hours of the ultrasonographic measurements were included in the study.

Results: A total of 392 pregnant women were included in the study. Ninety-eight pregnant women were examined by 1 st year resident, 100 pregnant by 2nd year resident, 93 pregnant by 3rd year resident and 101 pregnant by 4 th resident. Largest difference between the estimated fetal weight and birth weight was performed by the fourth year resident with $125.06 \pm 247.40$ grams.

Conclusions: The estimated fetal weight by ultrasonography has an important place in obstetric practice and it may vary according to the years of seniority of the resident. For this reason, ultrasonography should be used effectively and accurately during the training of the residents in the centers of education in obstetrics and gynecology and it is essential that the residents learn the ultrasound examination properly and completely.

Keywords: fetal weight, ultrasonography, resident, training, estimation

$\mathrm{F}$ or over 40 years, evaluation of the fetus and fetal weight estimation by ultrasonography has become routine in the obstetric practice [1,2]. Fetal growth is monitored by measurement of biometrical parameters such as biparietal diameter (BPD), femur length (FL), head circumference (HC) and abdomen (AC) circumference [3]. Several methods are used to calculate the estimated fetal weight(EFW) and some or all of the parameters such as BPD, FL, HC, AC are included in the EFW calculation $[2,4,5]$. By ultrasonographic fetal evaluation macrosomia, intrauterine growth retardation, amniotic fluid anomalies and fetal malformations can be determined. Average birth weight is an important parameter that may cause neonatal morbidity and mortality. According to fetal weight estimates, follow-up or birth decision can be given for the fetus

Received: November 24, 2018; Accepted: January 13, 2019; Published Online: January 28, 2020

How to cite this article: Çift T, Temur M, Yıldızbakan M, Türker AÜ, ÖztaşS, Acar Y, et al. Determination of error level of ultrasonographic fetal weight estimation according to the seniority of residents in obstetrics and gynecology. Eur Res J 2020;6(4):319-325. DOI: 10.18621/eurj.487211

Address for correspondence: Tayfur Çift, MD., University of Health Sciences, Bursa Yüksek Ihtisas Training and Research Hospital, Department of Obstetrics and Gynecology, Bursa Turkey.E-mail: tayfur_cift@yahoo.com 
$[6,7]$. In addition, the fetal weight estimation is helpful for the clinician in difficult cases such as macrosomic infants and determination of the route of delivery in terms of cephalopelvic disproportion [8]. Making the ultrasound measurements in the wrong plane or section, maternal obesity and amount of amniotic fluid affect the estimated fetal weight calculation $[2,5]$.

Fetal weight estimation, which is commonly used in obstetric practice, requires an effective ultrasonography. Therefore, effective and correct use of ultrasonography during residency training is gaining importance.

Although there are studies in the literature comparing the estimated fetal weight with the birth weight, there is no study comparing the differences in measurement according to the seniority of the residents in obstetrics and gynecology [2, 4, 9].

In this study, considering the difference between estimated fetal weight and birth weight, we aimed to determine the fallibility of the residents according to their seniority years.

\section{METHODS}

This research was planned as a prospective and approved by the Ethics Committee of Bursa Yüksek İhtisas Training and Research Hospital (Acceptance no: 2011-KAEK-25 2018/09-26). Study included women who gave birth in Bursa Yüksek İhtisas Training and Research Hospital, Obstetrics and Gynecology Clinic between 15.09.2018-15.11.2018. All participants were informed and their consent was obtained. Multifetal gestations and pregnancies with fetal anomaly, systemic diseases, preeclampsia or gestational diabetes were excluded in the study. Ultrasonographic measurements were performed with
GE Voluson Pro 730 (USA) brand ultrasound device and the estimated fetal weight was calculated with Hadlock $4[\log 10 \mathrm{BW}=1,326-0,00326(\mathrm{AC})(\mathrm{FL})+$ $0,0107(\mathrm{HC})+0,438(\mathrm{AC})+0,158(\mathrm{FL})]$ formula. Measurements were performed by the residents in the first, second, third and fourth year of training and repeated by the same specialist for each patient. Only those who gave birth within 48 hours of the ultrasonographic measurements were included in the study. Measurements of birth weights of newborns were performed within the first hour after delivery. Maternal age, gravida, parity and body mass index (BMI) were determined.

BPD measurement was performed in the midline of the falx cerebri, in which the thalamic nuclei were observed symmetrically on both sides of the falx, from the outer edge of the anterior parietal bone to the inner edge of the posterior parietal bone. In the same plan, $\mathrm{HC}$ measurement was performed simultaneously. AC measurement was performed in the transverse plane where vertebras, portal vein and stomach were seen, including echoes of the skin from the outer edges of the section. FL measurement was performed after the femoral diaphysis was clearly visualized and the distal epiphysis and femoral head were not included in the measurement.

\section{Statistical Analysis}

Statistical analysis of the data was done by SPSS software version 19.0 (Statistical Program for Social Sciences, Chicago, IL, USA). Mean +/- standard deviation values were used in descriptive statistics of the data. Distribution of the variables was checked by Kolmogorov-Smirnov test. In the comparison of the groups, Student normals $t$ test was used when the data shows normal distribution, whereas Mann Whitneyy $\mathrm{U}$ test was used when the data were not normally distributed. $p<0.05$ was statistically significant.

Tablo 1. Demographic data of patients

\begin{tabular}{lcccc}
\hline & N & Minimum & Maximum & Mean \pm Standart deviation \\
\hline Age (years) & 392 & 15 & 44 & $26.98 \pm 5.86$ \\
Gravida & 392 & 1 & 8 & $2.37 \pm 1.42$ \\
Parity & 392 & 0 & 5 & $1.16 \pm 1.21$ \\
$\begin{array}{l}\text { Body mass Index } \\
\left(\mathbf{k g} / \mathbf{m}^{\mathbf{2}}\right)\end{array}$ & 392 & 20.81 & 44.44 & $28.89 \pm 3.86$ \\
\hline
\end{tabular}




\section{RESULTS}

A total of 392 pregnant women were included in the study. Ninety-eight pregnant women were examined by $1^{\text {st }}$ year resident, 100 pregnant by $2^{\text {nd }}$ year resident, 93 pregnant by $3^{\text {rd }}$ year resident and 101 pregnant by $4^{\text {th }}$ year resident. Demographic data of patients are given in Table 1. Mean age of the patients was $26.98 \pm 5.86$. Estimated weights of the fetuses and birth weights and the difference between these two values are shown in Table 2. Mean difference between estimated fetal weight and birth weight was calculated as $64 \pm 215.99$ grams. Table 3 shows the measurement differences of the residents according to their seniority. Largest difference between the estimated fetal weight and birth weight was performed by the fourth year resident with $125.06 \pm 247.40$ grams. When the measurements were compared, we determined that the difference between the values of the 2 nd year resident and the fourth year resident $(p=0.007)$ and the difference between the values of the $3 \mathrm{rd}$ year and the fourth year resident $(p=0.006)$ were statistically significant (see Table 4).

Table 2. Estimated weight and actual weight values of fetuses

\begin{tabular}{lcccc}
\hline & N & Mean \pm Standart deviation & Minimum & Maximum \\
\hline $\begin{array}{l}\text { Estimated fetal weight } \\
\text { (EFW) (gram) }\end{array}$ & 392 & $3208.85 \pm 553.15$ & 810 & 4600 \\
Birth weight (gram) & 392 & $3144.74 \pm 565.77$ & 840 & 4630 \\
$\begin{array}{l}\text { Difference between EFW } \\
\text { and Birth weight (gram) }\end{array}$ & 392 & $64 \pm 215.99$ & -900 & 836 \\
\hline
\end{tabular}

Table 3. Weight measurement differences of the residents according to their seniority

\begin{tabular}{lcccccc}
\hline & N & $\begin{array}{c}\text { Mean } \pm \text { Standart } \\
\text { deviation }\end{array}$ & & $\begin{array}{c}\text { 95\% confidence interval } \\
\text { for average }\end{array}$ & Minimum & Maximum \\
\cline { 3 - 5 } & & & $\begin{array}{c}\text { Lower } \\
\text { Limit }\end{array}$ & $\begin{array}{c}\text { Upper } \\
\text { Limit }\end{array}$ & & \\
\hline $1^{\text {th }}$ year resident & 98 & $77.35 \pm 262.40$ & 24.74 & 129.96 & -650 & 547 \\
\hline $2^{\text {nd }}$ year resident & 100 & $27.24 \pm 189.46$ & -10.35 & 64.83 & -410 & 670 \\
\hline $3^{\text {th }}$ year resident & 93 & $23.60 \pm 114.48$ & 0.02 & 47.18 & -900 & 250 \\
\hline $4^{\text {th }}$ year resident & 101 & $125.06 \pm 247.40$ & 76.22 & 173.91 & -565 & 836 \\
\hline Total & 392 & $64.11 \pm 215.99$ & 42.66 & 85.56 & -900 & 836 \\
\hline
\end{tabular}

\section{DISCUSSION}

Estimated fetal weight is determined automatically by ultrasound device after the measurement of BPD, $\mathrm{HC}, \mathrm{AC}$ and FL parameters based on various formulas [3]. There may be a difference between the estimated fetal weight and actual birth weight. This may be due to fetal and maternal reasons, and may differ according to the clinician who applied ultrasonography $[1,2,9$, 10]. In our study, we determined the actual birth weights of newborns and the estimated fetal weight measured by ultrasonography by residents in obstetrics and gynecology, and compared the differences between them according to the seniority of the residents.

In a study by Özçam et al. [2], it was evaluated the 
Table 4. Comparison of weight differences between groups

\begin{tabular}{|c|c|c|c|c|c|}
\hline \multicolumn{2}{|c|}{ Senior groups by years } & \multirow{2}{*}{$\begin{array}{c}\text { Mean } \pm \\
\text { Standart } \\
\text { deviation }\end{array}$} & \multirow[t]{2}{*}{$p$ value } & \multicolumn{2}{|c|}{$\begin{array}{l}95 \% \text { confidence interval for } \\
\text { average }\end{array}$} \\
\hline & & & & Lower limit & Upper limit \\
\hline \multirow[t]{3}{*}{$1^{\text {th }}$ year resident } & $2^{\text {nd }}$ year resident & $50.11 \pm 30.23$ & 0.59 & -30.07 & 130.30 \\
\hline & $3^{\text {th }}$ year resident & $53.75 \pm 30.79$ & 0.49 & -27.91 & 135.42 \\
\hline & $4^{\text {th }}$ year resident & $-47.71 \pm 30.16$ & 0.68 & -127.70 & 32.28 \\
\hline \multirow[t]{3}{*}{$2^{\text {nd }}$ year resident } & $1^{\text {th }}$ year resident & $-50.11 \pm 30.23$ & 0.59 & -130.30 & 30.07 \\
\hline & $3^{\text {th }}$ year resident & $-3.63 \pm 30.64$ & 1.0 & -77.63 & 84.90 \\
\hline & $4 t^{\mathrm{h}}$ year resident & $97.82 \pm 30.01$ & $0.007^{*}$ & -177.41 & -18.24 \\
\hline \multirow[t]{3}{*}{$3^{\text {th }}$ year resident } & $1^{\text {th }}$ year resident & $-53.75 \pm 30.79$ & 0.49 & -135.42 & 27.91 \\
\hline & $2^{\text {nd }}$ year resident & $-3.63 \pm 30.64$ & 1.0 & -84.90 & 77.66 \\
\hline & $4^{\text {th }}$ year resident & $-101.46 \pm 30.57$ & $0.006^{*}$ & -182.54 & -20.39 \\
\hline \multirow[t]{3}{*}{$4^{\text {th }}$ year resident } & $1^{\text {th }}$ year resident & $47.71 \pm 30.16$ & 0.687 & -32.28 & 127.70 \\
\hline & $2^{\text {nd }}$ year resident & $97.82 \pm 30.01$ & $0.007^{*}$ & 18.24 & 177.41 \\
\hline & $3^{\text {th }}$ year resident & $101.46 \pm 30.57$ & $0.006^{*}$ & 20.39 & 182.54 \\
\hline
\end{tabular}

Table 5. Predictions of all residents according to BMI of patient

\begin{tabular}{lcccccc}
\hline & $\mathbf{n}$ & $\begin{array}{c}\text { Mean } \pm \text { Standart } \\
\text { deviation }\end{array}$ & $\begin{array}{c}\text { 95\% confidence interval for } \\
\text { average }\end{array}$ & Minimum & Maximum \\
\cline { 3 - 5 } & & & Lower Limit & Upper Limit & & \\
\hline Normal & 60 & $33.08 \pm 225.08$ & -25.06 & 91.22 & -450 & 525 \\
Overweight & 176 & $71.20 \pm 228.17$ & 37.25 & 105.14 & -650 & 670 \\
Obese & 156 & $68.04 \pm 197.91$ & 36.74 & 99.34 & -900 & 836 \\
Toplam & 392 & $64.11 \pm 215.99$ & 42.66 & 85.56 & -900 & 836 \\
\hline
\end{tabular}

effect of parity, maternal body mass index, weight gain during pregnancy, stage of delivery and amniotic fluid content on estimated fetal weight by ultrasonography. In this retrospective study of 100 pregnant women, it was determined that the parameters such as gender of the fetus, maternal parity, stage of delivery, preconceptional BMI, weight gain during pregnancy were not statistically significant in estimated fetal weight $(p<0.05)$. In addition, it was found that ultrasonographic estimation of fetal weight was closely correlated with actual birth weight in pregnant women with oligohydramnios and / or perfused amniotic membranes [2]. In our study, we found that the difference between ultrasonographic fetal weight estimation and actual birth weight decreased with the increase of seniority years of the residents. As an exception, as a result of the measurements made by the 4th year resident, we found that the estimated fetal weight increased and the difference between ultrasonographic measurements and the actual birth 
Tablo 6. Comparison of groups according to BMI

\begin{tabular}{llcccc}
\hline & & $\begin{array}{c}\text { Mean } \pm \text { Standart } \\
\text { deviation }\end{array}$ & $p$ value & \multicolumn{2}{c}{$\begin{array}{c}\text { 95\% confidence interval for } \\
\text { average }\end{array}$} \\
\cline { 5 - 6 } & & & 0.71 & -115.80 & 39.56 \\
\hline Normal & Overweight & $-38.12 \pm 32.31$ & 0.86 & -113.90 & 43.98 \\
\cline { 5 - 6 } Overweight & Obese & $-34.96 \pm 32.83$ & 0.71 & -39.56 & 115.80 \\
& Normal & $38.12 \pm 32.31$ & 1.0 & -53.98 & 60.30 \\
\cline { 5 - 6 } Obese & Obese & $3.15 \pm 23.76$ & 0.86 & -43.98 & 113.90 \\
& Normal & $34.96 \pm 32.83$ & 1.0 & -60.30 & 53.98 \\
\hline
\end{tabular}

weight was enlarged. When the measurement were compared, we determined that the difference between the values of the $2^{\text {nd }}$ year resident and the fourth year resident $(p=0.007)$ and the difference between the values of the $3^{\text {rd }}$ year and the fourth year resident $(p=$ 0.006 ) were statistically significant.

In our study, we used Hadlock 4 formula in fetal weight estimation. In the literature, there are studies about how accurate the various formulas predict the fetal birth weight. In a study by Blue et al. [9], they compared the Hadlock method with the racial / ethnic standard method of the Unice Kennedy Shriver National Institute of Child Health and Human Development. In the study, 1,514 pregnant women were evaluated and the Hadlock method was found to be superior to the racial/ethnic standart method of Unice Kennedy Shriver's National Health and Human Development method [9]. In a study conducted by Energin [5], 2-dimensional and 3D ultrasound measurements, and the accuracy of the estimated fetal weight (EFW) formulas used in these measurements were evaluated. In this study, 165 pregnant women were evaluated using the Hadlock I (BPD, AC, FL), Hadlock II (BPD, HC, AC, FL), Shepard (BPD, AC) formulas to determine $\mathrm{EFW}$ in 2-dimensional (2D) ultrasonography. In 3D ultrasonography, Lee I (TVol), Lee II (TVol, AC) and Lee III (TVol, AC, BPD) formulas were used for EFW measurements. No significant difference was found between the measurements performed with Lee I, Hadlock II, Hadlock I and newborn birth weights. They found a statistically significant difference between newborn birth weights and measurements performed with Lee II, Lee III and Shephard formulas. As a result of the study, it was clinically possible to use 3D ultrasonography in the calculation of EFW [10].

In another study by Blue et al. [9], Hadlock formula was compared with new methods in the estimation of fetal weight. In this study, Intergrowth21st (INTG) and Salomon technique were compared with the Hadlock formula, and they found that the Hadlock formula was more successful in the determination of small for gestational age (SGA) fetuses.

In a different study, Pretscher et al. [1], evaluated the success of sonographic measurements in predicting poor outcomes of pregnancy. However, the results of the study showed that such a prediction is not possible with ultrasonographic measurements [1]. In our study, we calculated the estimated fetal weight using the Hadlock formula and BPD, HC, AC, FL parameters. We found the mean difference between the estimated fetal weight and the actual newborn birth weight as $64 \pm 215.99$ grams.

In a study of 165 pregnant women, Energin [5] evaluated the factors affecting the estimated fetal weight measured by ultrasonography. Results of the study showed that gravida, parity, sex of the fetus, presence of meconium in amniotic fluid and fetal presentation did not have any effect on fetal weight. In addition, the study also reported that maternal obesity had no effect on fetal weight [5]. In contrast, another study by Özen et al. [6] found that maternal obesity had a negative effect on fetal weight 
estimation. In our study, we found that the margin of error in obese patients was higher than patients with normal weight. The comparison of the groups according to the difference between the estimated fetal weight was not statistically significant.

In our study, we evaluated the difference between the estimated fetal weight and the actual newborn birth weight according to the seniority of the residents in obstetrics and gynecology. A similar study was not found in the literature. We found that the difference between ultrasonographic fetal weight estimation and actual birth weight decreased with the increase of seniority years of the residents. As an exception, as a result of the measurements made by the 4th year resident, we found that the estimated fetal weight increased and the difference between ultrasonographic measurements and the actual birth weight was enlarged. Possible reason for that, is the decrease in the error margin of the measurements with the increase of the experience of the residents. Increase in the error of the 4th year resident may be related to the fact that the residents in their last year oftenly providing the coordination and organization, and the patient's first examination including ultrasound measurements is made by the residents in $1^{\text {st }}$ or $2^{\text {nd }}$ year.

In our study, it was also shown that with the increase in BMI in patients, estimated fetal weight averages increased and high BMI had a negative effect on EFW. Fact that the data were not found statistically significant in this study may be due to the low number of cases (see Tables 5 and 6).

\section{CONCLUSION}

In conclusion, the estimated fetal weight by $2 \mathrm{D}$ or 3D ultrasonography has an important place in obstetric practice and it may vary according to the years of seniority of the rezidents. For this reason, ultrasonography should be used effectively and accurately during the training of the residents in the centers of education in obstetrics and gynecology and it is essential that the residents learn the ultrasound examination properly and completely.

\section{Conflict of interest}

The authors disclosed no conflict of interest during the preparation or publication of this manuscript.

\section{Financing}

The authors disclosed that they did not receive any grant during conduction or writing of this study.

\section{Ethics statement}

All procedures performed in this study were in accordance with the ethical standards of the institutional and/or national research committee and with the 1964 Helsinki declaration and its later amendments or comparable ethical standards. No animal or human studies were carried out by the authors for this article.

\section{Scientific responsibility statement}

The authors declare that they are responsible for the article's scientific content including study design, data collection, analysis and interpretation, writing, some of the main line, or all of the preparation and scientific review of the contents and approval of the final version of the article.

\section{REFERENCES}

1. Pretscher J, Schwenke E, Baier F, Kehl S, Schneider M, Stumpfe FM, et al. Can sonographic fetal biometry predict adverse perinatal outcome? Ultraschall Med 2019;40:230-6.

2. Özçam H, Çimen G, Atakul N, Uzunçakmak C, Güldas A, Kesmezacar Ö. [The effect of parity, maternal BMI (Body Mass Index), weight gain in pregnancy, stage of birth and amniotic fluid on ultrasonographic fetal weight estimation]. İstanbul Med J 2015;16:105-10. [Article in Turkish]

3. Alper T, Yanık A, Malatyalığlu E, Dabak Ş. Fetal biyometri persantil değerlerimiz II: Femur uzunluğu. Perinatoloji Dergisi 1996;4:113-6.

4. Monier I, Ego A, Benachi A, Ancel PY, Goffinet F, Zeitlin J. Comparison of the Hadlock and INTERGROWTH formulas for calculating estimated fetal weight in a preterm population in France. Am J Obstet Gynecol 2018;219:476.e1-12.

5. Energin H. [Factors affecting fetal weight measured by ultrasonography]. Dicle Med J 2016;43:294-8.[Article in Turkish]

6. Özen S, Demirkıran F, İşçi H, Kavuzlu C. Fetal ağırlığın ultrasonografîk tahmini: 11 fetal ağırlık tahmin modelinin değerlendirilmes. Perinatoloji Dergisi 1993;1:150-4.

7. Ahn MO, Cha KY, Phelan JP. The low birth weight infant: is there a preferred route of delivery? Clin Perinatol 1992;19:41123.

8. Görgen H, Kuyumcuoğlu U, Ergün B, Api M. Fundus-pubis ölçümü ile fetal ağırlık tahmini. Perinatoloji Dergisi 1994;2:858.

9. Blue NR, Savabi M, Beddow ME, Katukuri V, Fritts CM, Izquierdo LA, et al. The Hadlock method is superior to newer 
methods for the prediction of the birth weight percentile. J Ultrasound Med 2019;38:587-96.

10. Energin H, Yapar Eyi EG. [Comparison of the estimated fetal weight measurements in 2 and 3 dimensional ultrasound at term pregnant women]. Jinekoloji Obstetrik ve Neonatoloji Tip Dergisi 2012;9:1472-7. [Article in Turkish]
11. Blue NR, Beddow ME, Savabi M, Katukuri V, Chao CR. Comparing the Hadlock fetal growth standard to the Eunice Kennedy Shriver National Institute of Child Health and Human Development racial/ethnic standard for the prediction of neonatal morbidity and small for gestational age. Am J Obstet Gynecol 2018;219:474.e1-12. 